\title{
Assessment of Inter Professional Competencies among Graduate Students in Nursing, Communication Disorders and Exercise Science in the US
}

\author{
Kem B. Louie, Ph.D., APN, CNE, FAAN \\ Professor \\ Department of Nursing \\ Betty Kollia, Ph.D., CCC-SLP. \\ Professor \\ Department of Communication Disorders and Sciences \\ Persephone Vargas, DNP, APN-BC. \\ Assistant Professor \\ Department of Nursing \\ Michael A. Figueroa, Ed.D., CSCS. \\ Professor \\ Department of Kinesiology \\ Toni LaSala, Ph.D, CSCS- ACSM-EP-C \\ Associate Professor \\ Department of Kinesiology \\ Racine Emmons, Ed.D, ACSM-RCEP \\ Associate Professor \\ Department of Kinesiology \\ William Paterson University \\ New Jersey \\ USA
}

\begin{abstract}
Background: Health care students are educated exclusively within their own disciplines.

Purpose: The purpose of the study was to examine the effectiveness of an Interprofessional Education (IPE) experience among graduate nursing, graduate communication disorders, and exercise science students.

Methods: A problem-based IPE project was developed by the faculty. Students worked as a team to develop a comprehensive treatment plan. Each team presented to the class after four weeks. The students completed the Interprofessional Collaborative Competencies Attainment Survey (ICCAS) to evaluate the IPE experience.

Results: 51 students participated in the IPE experience: 24 nursing, 17 communication disorders, and 10 exercise science students. A paired samples t-test showed a significant increase $(p<.05)$ in post-test scores in all competencies surveyed.

Discussion: The results show that health professional students perceived that their IPE competencies improved because of the IPE experience.

Conclusion: Incorporating IPE in the curriculum can promote interprofessional collaboration skills.
\end{abstract}

Keywords: Interprofessional Education, Nursing, Communication Disorders, Exercise Science, Competency framework, Interprofessional practice, Interprofessional collaboration, Interprofessional Collaborative Competencies 


\section{Introduction}

Currently, health care students and professionals are educated solely within their own disciplines to manage or treat specific medical issues where teamwork and collaboration are not a priority. Today's patients have complex health needs and typically require more than one discipline to address issues regarding their health status (Bridges, Davidson, Odegard, Maki \&Tomkowiak, 2011).The World Health Organization (WHO, 1988) recognized that collaborations taught at the student level were more likely to achieve effective collaborative practice in the healthcare settings. Studies indicate that health professionals who work in a collaborative environment have been shown to improve patient care, decrease costs, decrease patients' length of stay, and reduce medical errors (Mitchell et al., 2014; Barwell, Arnold \& Berry, 2013).

Interprofessional education (IPE) has been defined as "two or more professions who learn with, from and about each other to improve collaboration and quality of care." (Canadian Interprofessional Health Collaborative, 2010). IPE plays a major role in preparing health profession students in understanding what eachother's roles are as well as the skills needed to provide patient care in a collaborative team environment (Maharajan et al.,2017). Additionally, the WHO (WHO, 1988) regards IPE as one of the most promising strategies to achieve effective collaborative practice in healthcare settings. Furthermore, this is supported by the National Academies of Practice, the American Public Health Association, as well as the Institute of Medicine. The IOM stated that the education of health professionals to be members of an interdisciplinary team (Greiner\& Knebel, 2003). They also declared that when health care professionals work effectively as a team they are better able to communicate and understand each other's roles and to provide quality care to patients.

The goals of the IPE program are to form a collaborative team from different health professions where each possess their own specific knowledge skills and abilities but work together to achieve a common patient-centered goal. Members of the team are all involved in the decision- making process and will discuss their observations and individual expertise, then develop an appropriate treatment plan for their patients (Greiner et al., 2003).

Evidence underscores the effectiveness of IPE on professional practice and health outcomes. In a Cochrane systematic review of 6 studies, two studies showed no impact on patient care or practice; however four of the studies showed positive outcomes on teamwork, error rates, and mental health competencies (Reeves et al., 2008). Although general conclusions cannot be drawn due to the limited number of studies, the authors summarized that students and practitioners were open to learning the knowledge and skills required for working in a collaborative environment where they can make a positive impact on health care (Reeves et al., 2008). Another systematic review on IPE showed positive reactions, change in perceptions and attitudes as well as improvement in knowledge and skills for collaboration from learners Hammick, Freeth, Kopppel, Reeves \& Barr, 2007).

Focusing on the use of IPE among undergraduate health sciences students, a literature review showed that most IPE activities were represented by two healthcare professionals and most were done on medical and nursing students (Abu-Rish et al., 2012). Most IPE activities offered to students were a one-time event and the most common IPE strategy used was a small group discussion followed by a case or problem-based learning. The most common outcome reported was on students' attitudes towards IPE, followed by improvement in knowledge of IPE competencies. It was also noted that in most studies, there was an absence of theoretical framework, which would suggest a disconnect between the application of theory to practice (Abu-Rish et al., 2012).

There are several frameworks guiding interprofessional education. The framework used in this study is focused on interprofessional practice developed by the Canadian Interprofessional Health Collaboration (CAIPE, 2008). This competency framework provides a structure for assessing an individual's ability to collaborate based on the integration of knowledge, skills, attitudes, and values leading to judgments in varying contexts. The competency framework is composed of six integrated competency domains that together result in interprofessional collaboration. The six competency domains include: 1) patient/family centered approach (integrating the patient's input in the plan of care); 2) interprofessional communication (utilizing effective communication with team members demonstrating trust and respect); 3) team functioning (incorporating respect of roles and responsibilities, cooperation, coordination, trust, shared decision making and partnership); 4) role clarification (understanding own role and role of others and utilizing this knowledge to provide appropriate patient care); 5) collaborative leadership (applying shared decision making and accountability) and 6) interprofessional conflict resolution (engaging in respectful and effective resolution of disagreements )(CAIPE, 2008).Each competency can be learned, developed, and applied for effective interprofessional collaboration. 
IPE is essential in preparing health professional students for future collaborative practice. Most of the published studies evaluating IPE are conducted on medical and nursing students (Hammick et al., 2007). To the authors' knowledge, there are no published studies on IPE with graduate nursing students, graduate communication disorder students and undergraduate exercise science students as participants. The purpose of this study was to evaluate the effectiveness of an Interprofessional Education (IPE) project among graduate nursing, graduate communication disorders and undergraduate exercise science students.

\section{Methods}

\subsection{Procedures}

A problem-based IPE experience was developed by the faculty from the College of Science and Health (Nursing, Communication Disorders\& Sciences, and Exercise Science). The participating faculty from each discipline met several times prior to the initiation of the activity to discuss the objectives and methods of the IPE activity. A faculty member from each department collaborated and provided input in the development of the case studies that involved patients with cardiovascular illnesses and stroke.

In the Fall Semester of 2017, the IPE activity was implemented to include graduate nursing students, graduate communication disorders students, and undergraduate exercise science students who were in their last internship course. The students were provided reading assignments along with discussions of the purpose and value of IPE for the improvement of patient care quality and treatment outcomes.

The students were randomly assigned to a team. There were a total of ten teams, nine teams of five students and one team with six students, each having at least one student from the three disciplines. Each team was assigned different case studies, which were shared by students via the learning management system. The students had to communicate and meet with their team outside of class time. They were instructed to work within the scope of their discipline and collaborate in the development of a comprehensive treatment plan with priority goals. At the end of 4 weeks, the IPE experience culminated with a presentation from each team. After the presentations, the students were asked to complete the Interprofessional Collaborative Competencies Attainment Survey (ICCAS) to evaluate the IPE experience. Each of the 51 students completed the retrospective pre-test and post-test ICCAS survey.

\subsection{Participants}

Fifty- one (51) students participated in the IPE experience: 24 nursing, 17 communication disorders, and 10 exercise science. The majority of the participants were female $(80 \%, \mathrm{n}=41)$.

\subsection{Clinical Cases}

Five clinical cases were given to each team, as a clinical case for diagnosis and development of a treatment plan within each of the disciplines. For example, in case 1 the students were provided history of a middle aged man with hyperlipidemia, severe 3-vessel coronary artery disease, perioperative stroke, a list of current medications, information on his history of physical activity, the results of a graded exercise stress test, to assess cardiorespiratory function and other physiological indices, communication abilities including language comprehension and language production difficulties, as well as information on his speech repetition skills.

\subsection{Survey Tool}

The Interprofessional Collaborative Competencies Attainment Survey (ICCAS) (Archibald, et al 2014) is a 20 item, self-report tool that measures students' skills in six domains: communication, collaboration, roles and responsibilities, collaborative patient family-centered approach, conflict management/resolutions, and team functioning. The ICCAS responses were on a 7-point Likert scale from $1=$ strongly disagree to $7=$ strongly disagree. There was an option for the students to rate the item as "not applicable". The tool is based on the Canadian Interprofessional Health Collaborative framework ${ }^{11}$ and utilizes a retrospective pre-test and post-test method (Archibald et al., 2014). The students completed the survey after the IPE learning experience, which addressed their perception prior to, and after the IPE activity, responding to the same 20 competencies. The ICCAS survey (Archibald et al., 2014)is unique in the field of interprofessional education and is one of the first validated measures of IPE competencies utilizing a retrospective pre-test and post- test design. Validity measures were reported to be "exploratory factor analysis" which yields two factors for the pre-program assessment and a single factor for the post program assessment. The two factors were one's own roles and skills in collaboration and one's involvement with the rest of the team or patients' families. 


\section{Statistical Analysis}

Survey responses for the 51 participants on the pre- and post- IPE experience were analyzed via a paired samples $t$-tests in SPSS (version 25). Cronbach's alpha coefficient was obtained as an index of the internal consistency of the test items.

\section{Results}

Descriptive statistics were obtained for the 51 students' responses. The mean ratings for each item if the survey are summarized in Table 1.

Table1. Means of pre-test and post-test items

\begin{tabular}{|l|l|l|}
\hline COMPETENCIES & PRE (n=51) & POST (n=51) \\
\hline Communication & & \\
\hline Effective communication & 4.91 & 6.06 \\
\hline Active listening & 5.47 & 6.24 \\
\hline Expressing ideas and concerns & 5.76 & 6.20 \\
\hline Providing constructive feedback & 5.26 & 6.04 \\
\hline Expressing ideas and concerns & 5.60 & 6.21 \\
\hline Collaboration & & \\
\hline Seeking out member to address issues & 5.26 & 6.02 \\
\hline Working effectively to enhance care & 5.27 & 6.10 \\
\hline Learning with, from and about team members to enhance care & 5.23 & 6.31 \\
\hline Roles and Responsibilities & & \\
\hline Identifying and describing abilities and contributions to the team & 5.50 & 6.43 \\
\hline Accountability of contributions to the team & 5.67 & 6.37 \\
\hline Understanding the abilities and contributions of members & 5.24 & 6.27 \\
\hline $\begin{array}{l}\text { Recognizing how others' skills and knowledge complement and } \\
\text { overlap }\end{array}$ & 5.29 & 6.23 \\
\hline Collaborative Patient-Centered Approach & & \\
\hline $\begin{array}{l}\text { Using IP team approach to: } \\
\text { - assess the health situation }\end{array}$ & & \\
\hline - provide whole person care & 5.13 & 6.31 \\
\hline - include the patient/family in decision-making & 5.01 & 6.16 \\
\hline Conflict Management/Resolution & 5.56 & 6.28 \\
\hline Active listening to members perspectives & & \\
\hline Considering ideas of team members & 5.33 & 6.25 \\
\hline Addressing conflict in a respectful manner & 5.39 & 6.29 \\
\hline Team Functioning & 5.59 & 6.29 \\
\hline Developing an effective care plan as a team & 5.37 & 6.22 \\
\hline Negotiating responsibilities within overlapping scopes of practice & 5.18 & 6.12 \\
\hline
\end{tabular}

The results of the paired sample $t$-tests show that the mean scores of all 20 competencies increased as the students reflected upon the IPE learning experience (Table 1). Furthermore, a paired samplest-test was used to analyze the difference between the pre-test and post-test scores. These results indicate a significant difference $(p<.05)$ in all of the 20 competencies between the pre-test and post-test pairs of the ICCAS (Table 2).

Cronbach's alpha coefficient for all survey items was .98, indicating that the items have a relatively high internal consistency, similar to the original tool. 
Table2. Paired-Samples t-test results

\begin{tabular}{|l|l|l|l|}
\hline COMPETENCIES & $\mathrm{t}$ & $\mathrm{df}$ & $\begin{array}{l}\text { Sig. } \\
\text { (2-tailed) }\end{array}$ \\
\hline Communication & & & \\
\hline Pair 1 - Pre/Post Effective communication & -5.585 & 44 & $.000^{*}$ \\
\hline Pair 2 Pre/Post Active listening & -4.776 & 44 & $.000^{*}$ \\
\hline Pair 3 - Pre/Post Expressing ideas and concerns & -2.496 & 48 & $.016^{*}$ \\
\hline Pair 4-Pre/Post Providing constructive feedback & -3.857 & 49 & $.000^{*}$ \\
\hline Pair 5 - Pre/Post Expressing ideas and concerns & -3.348 & 47 & $.002^{*}$ \\
\hline Collaboration & & & \\
\hline Pair 6 - Pre/Post Seeking out member to address issues & -4.840 & 45 & $.000^{*}$ \\
\hline Pair 7 - Pre/Post Working effectively to enhance care & -4.766 & 42 & $.000^{*}$ \\
\hline $\begin{array}{l}\text { Pair 8 - Pre/Post Learning with, from and about team members } \\
\text { to enhance care }\end{array}$ & -5.737 & 47 & $.000^{*}$ \\
\hline Roles and Responsibilities & & & \\
\hline $\begin{array}{l}\text { Pair 9 - Pre/Post Identifying and describing abilities and } \\
\text { contributions to the team }\end{array}$ & -5.647 & 50 & $.000^{*}$ \\
\hline Pair 10 - Pre/Post Accountability of contributions to the team & -3.627 & 50 & $.001^{*}$ \\
\hline $\begin{array}{l}\text { Pair 11 - Pre/Post Understanding the abilities and contributions } \\
\text { of members }\end{array}$ & -4.773 & 49 & $.000^{*}$ \\
\hline $\begin{array}{l}\text { Pair 12 - Pre/Post Recognizing how others' skills and } \\
\text { knowledge complement and overlap }\end{array}$ & -4.642 & 50 & $.000^{*}$ \\
\hline Collaborative Patient-Centered Approach & & & \\
\hline $\begin{array}{l}\text { Using IP team approach to: } \\
\text { Pair 13 - Pre/Post assess the health situation }\end{array}$ & -6.172 & 46 & $.000^{*}$ \\
\hline Pair 14 - Pre/Post provide whole person care & & & \\
\hline Pair 15 - Pre/Post include the patient/family in decision-making & -4.046 & 48 & $.000^{*}$ \\
\hline Conflict Management/Resolution & & & \\
\hline Pair 16 - Pre/Post Active listening to members perspectives & -5.120 & 48 & $.000^{*}$ \\
\hline Pair 17 - Pre/Post Considering ideas of team members & -4.927 & 48 & $.000^{*}$ \\
\hline Pair 18 - Pre/Post Addressing conflict in a respectful manner & -5.055 & 48 & $.000^{*}$ \\
\hline Team Functioning & & & \\
\hline Pair 19-Pre/Post Developing an effective care plan as a team & -4.924 & 47 & $.000^{*}$ \\
\hline $\begin{array}{l}\text { Pair 20 Pre/Post Negotiating responsibilities within } \\
\text { overlapping scopes of practice }\end{array}$ & -4.318 & 47 & $.000^{*}$ \\
\hline 05 & & & \\
\hline
\end{tabular}

$* \mathrm{p}<.05$

\section{Discussion}

Most healthcare students are currently being educated solely in their owndisciplines. Only a few studies have evaluated IPE activities in more than two healthcare professions in the university setting(Maharajan et al. 2017).Other meta-analysis of IPE students conducted also include multiple health professions (Reeves et al., 2008; Abu-Rish et al., 2012). The present study involved participation of students from three healthcare professions.

The results of this study corroborate those of other studies that an IPE activity is effective in improving knowledge and attitude towards collaboration across professions. The results show that healthcare students perceive improvement in all areas of interprofessional competencies as a result of their participation in the IPE experience. These competencies include communications, collaboration, roles and responsibilities, collaborative patient/family centered approach, conflict management resolution and team functioning. Even though the majority of the students had a moderate level of experience working with IPE teams in their work settings or internships, the results indicate that their perceived competencies increased as reflected on the post test scores on the survey. The results also indicate that even a single IPE activity can significantly improve perceived IPE competencies among the healthcare students. 
Most studies on IPE interventions utilized a single IPE activity and a cross-sectional design(Abu-Rish et al, .2012). There is a paucity of studies that use long-termed IPE activities on healthcare students. Long-termed interventions and longitudinal follow-up are needed to identify if the outcomes could lead to changes in practice. Future research could be focused including other health care disciplines and on longitudinal research examining the IPE competencies or specific competencies as they performed in their respective work settings. A limitation of this study is the small sample size, as well as the fact that this study was conducted in a single university, and therefore, the generalizability of our findings should be viewed with caution.

\section{Conclusion}

An improvement in the perceived IPE competencies of graduate and undergraduate healthcare students was noted with one IPE activity. Incorporating IPE as a component of the curriculum can positively impact future members of the health care team to value the benefits of collaboration and team work. The IPE activity can prove to be a valuable experience for students, since healthcare is intertwined with a variety of disciplines whose focus is improved patient care. Introducing this in an academic environment can result in a more efficient transition into the workforce.

\section{References}

Abu-Rish, E., Kim, S., Lapio, C., et al.(2012).Current trends in interprofessional education of health sciences students: A literature review.Journal of InterprofessionalCare. 26 (6); 444-451. doi:10 .3109/ 13561820. 2012.715604

Archibald,D., Trumpower,D.,\& MacDonald,CJ. (2014).Validation of the interprofessionalcollaborate competency attainment survey (ICCAS). 28(6) 553-558. doi: 10.1080/13561820.2016.1233096

Barwell, J., Arnold, F.,\& Berry, H. (2013). How interprofessional learning improvescare. Nursing Times. 2013; 109:14-16. Retrieved from: https://www.nursingtimes.net/Journals/2013/05/30/p/q/j/290513-Howinterprofessional-learning-improves-care.pdf

Bridges, DR., Davidson, RA., Odegard, PS., Maki, IV., \& Tomkowiak, J. (2011). Interprofessional collaboration: three best practice models of interprofessional education. Medical Education Online. 16 (1). doi:10.3402/meo.v16i0.6035.

Canadian Interprofessional Health Collaborative (2010). A National Interprofessional Competency Framework. Canadian interprofessional Health Collaborative.Retrievedfrom:https://www.cihc.ca/files/CIHC _IPCompetencies_Feb1210.pdf

Center for Advancement of Interprofessional Education (CAIPE).(2008). Retrieved from https://www.caipe.org/

Greiner, AC., \& Knebel, E. (2003). Health Professions Education: A Bridge to Quality. Institute of Medicine (US) Committee on the Health Professions Education Summit. 2003; 225, 230. Washington (DC): National Academies Press (US). Available from: https://www.ncbi.nlm. nih.gov/b ooks/NBK22 1528/ doi : 10.17226/10681

Hammick, M., Freeth, D., Koppel, I., Reeves, S., \& Barr, H. (2007). A best evidence systematic review of interprofessional education: BEME Guide no. 9. Medical Teacher. 2007; 29(8): 735-751. doi: 10.1080/01421590701682576

Maharajan, MK., Rajiah, K., Khoo SP, Chellappan, DK., DeAlwis, R. Chui, HC., Tan, LL. Tan, YN \& Lau, SY. (2017). Attitudes and Readiness of Students of HealthcareProfessions towards Interprofessional Learning. PLoS ONE. 2017; 12(1), e0168863. doi:10.1371/journal.pone.0168863

Mitchell, P., Wynia, M., Golden, R., McNellis, B., Okun,S.,Webb, E., Rohrbach, V.,\&Von Kohorn, I. (2012). Core principles \& values of effective team-based healthcare. Discussion Paper, Institute of Medicine.. Washington, DC. www.iom.edu/tbc

Reeves, S., Zwarenstein, M., Goldman, J., Barr, H., Freeth, D., Hammick, M., \& Koppel. I. (2008). Interprofession al education: effects on professional practice and health care outcomes. Cochrane Database System Review. 1(1). doi:10.1002/14651858.CD002213.pub2

World Health Organization (WHO). (1988).Learning Together to Work Together for Health. Report of a WHO study group on multiprofessional education for health personnel: the team approach. Technical Report Series. 769: 1-72. Geneva: Retrieved from https://www.ncbi.nlm.nih.gov/pmc/articles/PMC2720355/\#B6 